\title{
Pressure-Tuning Raman Spectra of Diiodine Thioamide Compounds: Models for Antithyroid Drug Activity
}

\author{
Ghada J. Corban,, ${ }^{1}$ Constantinos Antoniadis, ${ }^{1}$ Sotiris K. Hadjikakou, ${ }^{1}$ Nick Hadjiliadis, ${ }^{1}$ \\ Jin-Fang Meng, ${ }^{2}$ and Ian S. Butler ${ }^{2}$ \\ ${ }^{1}$ Inorganic and Analytical Chemistry Section, Department of Chemistry, University of Ioannina, Ioannina 45110, Greece \\ ${ }^{2}$ Department of Chemistry, McGill University, 801 Sherbrooke Street West, Montreal, QC, Canada H3A 2K6
}

Received 12 April 2006; Revised 5 July 2006; Accepted 26 July 2006

The pressure-tuning Raman spectra of five solid, diiodine heterocyclic thioamide compounds (mbztS) $\mathrm{I}_{2}(\mathrm{mbztS}=\mathrm{N}$-methyl2-mercaptobenzothiazole) (1); $\left[(\mathrm{mbztS})_{2} \mathrm{I}\right]^{+}\left[\mathrm{I}_{7}\right]^{-}(2) ;\left(\right.$ pySH) $\mathrm{I}_{2}$ (pySH = 2-mercaptopyridine) $(3) ;\left[(\mathrm{pySH})(\mathrm{pyS}]^{+}\left[\mathrm{I}_{3}\right]^{-}(\mathbf{4}) ;\right.$ $($ thpm $)\left(I_{2}\right)_{2}$ or possibly $\left[(\text { thpm }) I_{2}\right]^{+}\left[I_{3}\right]^{-}$(thpm = 2-mercapto-3,4,5,6-tertahydropyrimidine $(5)$ have been measured for pressures up to $\sim 50$ kbar using a diamond-anvil cell. Compounds 1, 4, and 5 undergo pressure-induced phase transitions at $\sim 35$, $\sim 25$, and $\sim 32 \mathrm{kbar}$, respectively. Following the phase transition in 1, the pressure dependences of the vibrational modes, which were originally located at 84,111 , and $161 \mathrm{~cm}^{-1}$ and are associated with the $S^{\cdots}$ I-Ilinkage, are $2.08,1.78$, and $0.57 \mathrm{~cm}^{-1} / \mathrm{kbar}$, respectively. These pressure dependences are typical of low-energy vibrations. The pressure-tuning FT-Raman results for the pairs of compounds $1,2,3$, and 4 are remarkably similar to each other suggesting that the compounds are most probably perturbed diiodide compounds rather than ionic ones. The Raman data for $\mathbf{5}$ show that it is best formulated as $($ thpm $)\left(I_{2}\right)_{2}$ rather than $\left[(\text { thpm })_{2} \mathrm{I}\right]^{+}\left[\mathrm{I}_{3}\right]^{-}$.

Copyright (c) 2006 Ghada J. Corban et al. This is an open access article distributed under the Creative Commons Attribution License, which permits unrestricted use, distribution, and reproduction in any medium, provided the original work is properly cited.

\section{INTRODUCTION}

Iodine chemistry is proving to be of considerable interest lately, in part, because of the discovery of low-temperature, semi- and super-conducting polyiodides, which quickly led to the deliberate doping of conjugated polymers with elemental iodine, and ultimately resulted in the award of the 2000 Nobel Prize in Chemistry to Professor Heeger et al for their research on these materials [1]. A second important field in which iodine chemistry plays a pivotal role is in the activity of antithyroid drugs and there is now a major research effort focused on determining structure-activity relationships of thioamides with iodine $[2,3]$. The antithyroid drugs that are most commonly used today are the thioamide derivatives, 6- $n$-propylthiouracil, $\mathrm{N}$-methyl-imidazoline-2-thione (methimazole), and 3-methyl-2-thioxo-4-imidazoline-1-carboxylate (carbimazole). For the past few years, we have been exploring the iodine chemistry of thioamides in an effort to bring about a clearer understanding of the interactions involved in antithyroid drug treatment. As part of this research, we have reported the results of a fundamental study on the effect of high external pressures (up to $\sim 50 \mathrm{kbar}$ ) on the ambient-temperature FT-Raman spectra of four solid, diiodine-heterocyclic thioamide compounds [4]. In the case of one of these compounds, [(bztzdtH) $\left.\mathrm{I}_{2}\right\} \cdot \mathrm{I}_{2}$ (bztzdtH = benzothiazole-2-thione), we discovered that $\mathrm{I}_{2}$ disproportionation occurs with increasing pressure and $\mathrm{I}_{3}{ }^{-}$ions are produced. In addition, empirical correlations were established between the wavenumber of the I-I stretching vibration, the I-I bond length, and the applied external pressure. In this present paper, we have extended these pressure-tuning Raman spectroscopic studies to an examination of a second series of five, solid diiodineheterocyclic thioamide compounds: $(\mathrm{mbztS}) \mathrm{I}_{2}(\mathrm{mbztS}=\mathrm{N}$ methyl-2-mercaptobenzothiazole $) \quad(\mathbf{1}) ; \quad\left[(\mathrm{mbztS})_{2} \mathrm{I}\right]^{+}\left[\mathrm{I}_{7}\right]^{-}$ (2); (pySH) $\mathrm{I}_{2} \quad$ (pySH = 2-mercaptopyridine) (3); $\left[(\mathrm{pySH})(\mathrm{pyS}]^{+}\left[\mathrm{I}_{3}\right]^{-}(4) ;(\right.$ thpm $)\left(\mathrm{I}_{2}\right)_{2}$ or $\left[(\text { thpm }) \mathrm{I}_{2}\right]^{+}\left[\mathrm{I}_{3}\right]^{-}$ (thpm = 2-mercapto-3,4,5,6-tertahydropyrimidine) (5). These systems are also of potential importance as model compounds for the development of structure-activity relationships associated with the interaction of antithyroid drugs with iodine. They contain iodine atoms in several different structural arrangements and three of them have already been characterized by single-crystal X-ray diffraction, namely, compounds $1[5,6], 2[5-7]$, and 4 [8]. 


\section{EXPERIMENTAL}

The diiodine-heterocyclic thioamides $\mathbf{1}-\mathbf{5}$ were prepared according to the literature procedures $[2,5-8]$. Complete details of the pressure-tuning FT-Raman measurements, including the ruby $\mathrm{R}_{1}$ fluorescence-pressure calibration procedure, have been described elsewhere $[4,9]$. A diamondanvil cell (High Pressure Diamond Optics, Inc, Tucson, Ariz, USA) was used to generate the applied pressures. FT-Raman spectra were recorded on a Bruker IFS-88 FT-IR spectrometer equipped with an FRA-105 Raman module connected via two $1 \mathrm{~m}$ photo-optic cables to a Nikon Optiphot-II optical microscope using a Nikon 20X super-long-range objective. A near-IR $\left(\mathrm{Nd}^{3+}\right.$ : YAG) laser, emitting at $1064.1 \mathrm{~nm}$ with a power $\sim 25 \mathrm{~mW}$, was used to excite the Raman spectra and typically a $2.6 \mathrm{~cm}^{-1}$ spectral resolution was employed while collecting 1000 scans. The band positions are considered to be accurate to at least $\pm 1 \mathrm{~cm}^{-1}$.

\section{RESULTS AND DISCUSSION}

In our previous pressure-tuning FT-Raman work on diiodine thioamide compounds [4], we pointed out that electron charge-transfer between the $\mathrm{S}$ atom of a thioamide and diiodine will result in stabilization of the lone pair of electrons on the $S$ atom by overlapping of the $S$ donor orbital with the $\sigma^{*}$-orbital of diiodine. This situation will lead to a lengthening of the thione double bond in the thioamide and subsequent bond formation between the $S$ atom and diiodine, together with a concomitant lengthening of the I-I bond. It was also shown that there are direct empirical correlations between the S-I, C-S, and I-I bond distances, namely, if the $\mathrm{S}-\mathrm{I}$ distances are shorter than the $\mathrm{C}-\mathrm{S}$ ones are, then the I-I distances will be longer than normal and there will be strong electron donation and vice versa. The application of high external pressures to the diiodine thioamide compounds would, therefore, be expected to produce some significant changes in bond distances and particularly on the positions of the low-frequency modes associated with the iodine atoms. There have been only a few high-pressure vibrational studies reported on diiodine systems and these have involved chiefly oxides $[10,11]$ and sulfides [12]. The interaction of polyiodides with polyvinyl alcohols has also been investigated under high pressure [13]. In addition, the effect of high pressures on the Raman spectrum of solid diiodine itself has been the subject of several investigations $[14,15]$. In the present work, the FT-Raman spectra of compounds 1-5 were first recorded under ambient conditions and then pressure-tuning FT-Raman studies were undertaken on each of the species. An excellent review of the Raman spectra expected for different diiodine compounds has been published recently by Deplano et al [16].

FT-Raman spectra of compound $\mathbf{1}$ in the $50-250 \mathrm{~cm}^{-1}$ region are shown in Figure 1 for selected pressures up to $\sim 51.3 \mathrm{kbar}$. Initially, there are three bands observed at $84 \mathrm{w}$, $111 \mathrm{mw}$, and $161 \mathrm{vs} \mathrm{cm}^{-1}$. The Raman spectrum is closely similar to that reported for the $(\mathrm{dtt}) \mathrm{I}_{2}(\mathrm{dtt}=1,3$-ditholane2-thione) for which the presence of a S ${ }^{\cdots} \mathrm{I}$-I linkage has been established [17]. Upon increasing the pressure, the three

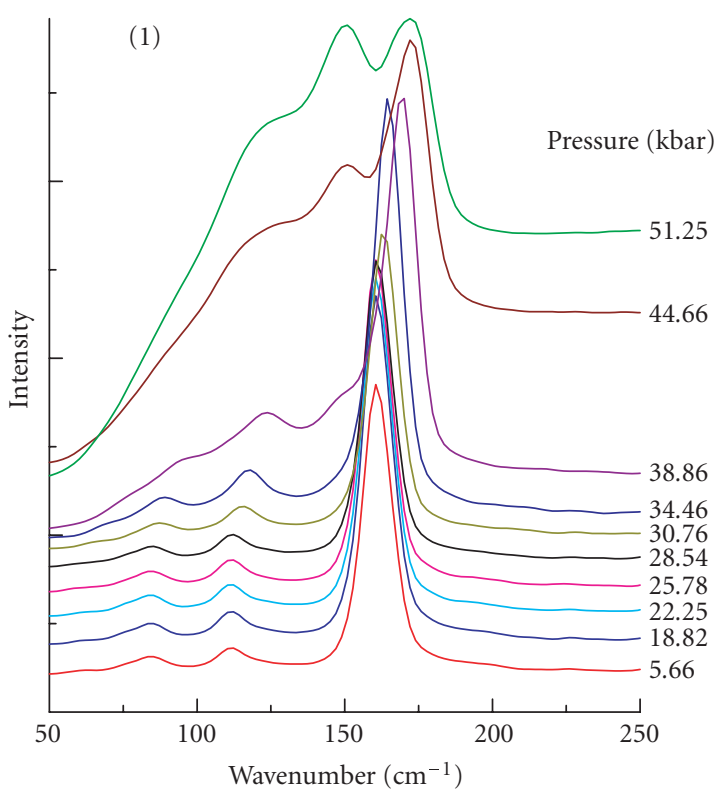

Figure 1: Pressure-tuning FT-Raman spectra of $\mathbf{1}$ in the low-energy region.

bands for compound 1 gradually shift to higher wavenumbers, as is typically the case [18]. At $\sim 35 \mathrm{kbar}$, the band originally at $84 \mathrm{~cm}^{-1}$ vanishes and a new band develops at $\sim 150 \mathrm{~cm}^{-1}$ which, eventually at $\sim 51 \mathrm{kbar}$, has a comparable intensity to that of the originally very strong peak, which has now shifted to $171 \mathrm{~cm}^{-1}$. These spectral changes can also be seen quite in the $\nu\left(\mathrm{cm}^{-1}\right)$ versus $\mathrm{P}$ (pressure, kbar) plot (Figure 2), which indicates that compound 1 undergoes a pressure-induced structural change at $\sim 35 \mathrm{kbar}$. From X-ray crystallographic data for $1[5,6]$, the I-I distance is $2.7912(9)$ $\AA$ which, from the linear plot of I-I bond length versus position of the $v(\mathrm{I}-\mathrm{I})$ mode given in [4], would lead to an I-I stretching vibration being expected at $\sim 160 \mathrm{~cm}^{-1}$ at ambient pressure, just as it is observed for this adduct. Before the phase transition for compound 1 occurs at $\sim 35 \mathrm{kbar}$, the three vibrations originally located at 84,111 , and $161 \mathrm{~cm}^{-1}$ are completely pressure insensitive. Following the phase transition, however, the pressure dependences are 2.08, 1.78, and $0.57 \mathrm{~cm}^{-1} / \mathrm{kbar}$, respectively, which are typical of low-energy vibrations. There are other weak Raman features detected at ambient pressure at 255, 311, 392, 511, 539, 636, and $708 \mathrm{~cm}^{-1}$, which are presumably associated chiefly with lowenergy bending vibrations of the thioamide group. Furthermore, it is also worthwhile pointing out that the disappearance of the $311 \mathrm{~cm}^{-1}$ band of compound 1 at $\sim 35 \mathrm{kbar}$ provides further evidence for the existence of the phase transition at this pressure.

In the case of compound 2, it was initially thought that this would prove to be compound 1 with an additional $\mathrm{I}_{2}$ molecule attached to the $\mathrm{S}^{\cdots} \mathrm{I}-\mathrm{I}$ unit leading to a S ${ }^{\cdots} \mathrm{I}-\mathrm{I}-\mathrm{I}-\mathrm{I}$ linkage. However, X-ray crystallographic analysis has subsequently shown that this compound is actually $\left[(\mathrm{mbztS})_{2} \mathrm{I}\right]^{+}\left[\mathrm{I}_{7}\right]^{-}[5,6]$. The same compound was reported earlier by Demartin et al [7]. Three Raman bands are observed at ambient pressure at $85 \mathrm{w}, 112 \mathrm{mw}$, and $161 \mathrm{vs} \mathrm{cm}^{-1}$. 
In addition, there are weak features at 257, 311, 391, 511, 539 , and $637 \mathrm{~cm}^{-1}$. The Raman data are essentially identical to those of compound 1. Upon application of pressure to 2, the Raman spectra continue to be closely similar to those of 1, including the existence of a pressure-induced structural change at $\sim 35 \mathrm{kbar}$. Therefore, from a vibrational standpoint, compounds $\mathbf{1}$ and $\mathbf{2}$ are essentially identical, not surprisingly since their formulations are really $\mathrm{S} \cdot \mathrm{I}_{2}$ and $\mathrm{I}^{-} \cdot 3 \mathrm{I}_{2}$. Delplano et al [16] have emphasized the experimental difficulties inherent in measuring the laser Raman spectra of polyiodides, that is, some $\mathrm{I}_{2}$ may be lost during the measurements, for example, $\mathrm{I}_{7}{ }^{-} \rightarrow \mathrm{I}_{5}{ }^{-}+\mathrm{I}_{2} ; \rightarrow \mathrm{I}_{5}{ }^{-} \rightarrow \rightarrow \mathrm{I}_{3}{ }^{-}+\mathrm{I}_{2}$. There was no spectroscopic evidence, however, for the formation of any free $\mathrm{I}_{2}$ in this particular case-a strong Raman band would have been observed at $\sim 180 \mathrm{~cm}^{-1}[1,14,15]$.

The low-energy FT-Raman spectra of (pySH) $\mathrm{I}_{2}$ (pySH = 2-mercaptopyridine) $(3)\left[(\mathrm{pySH})(\mathrm{pyS}]^{+}\left[\mathrm{I}_{3}\right]^{-}(4)\right.$ are also quite similar to one another. It is possible that compound 3 may have disproportionated to 4 upon initial pressurization in the DAC, as has been reported previously for [(bztzdtH) $\left.\mathrm{I}_{2}\right\} \cdot \mathrm{I}_{2}$ (bztzdtH = benzothiazole-2-thione) [4]. On the basis of X-ray crystallographic data for 4 , the $\mathrm{I}_{3}$ moiety is slightly bent. For a linear $\mathrm{I}_{3}{ }^{-}$entity, only one very strong Raman band would be expected at $\sim 110 \mathrm{~cm}^{-1}$ from the symmetric inphase $v(\mathrm{I}-\mathrm{I})$ stretching mode [17]. In the case of 4, however, there is an intense doublet at 155 and $164 \mathrm{~cm}^{-1}$, and several other weaker features are observed at $77 \mathrm{sh}, 110 \mathrm{vw}, 176 \mathrm{sh}$, and $234 \mathrm{vvw} \mathrm{cm} \mathrm{cm}^{-1}$. The appearance of this strong band at $164 \mathrm{~cm}^{-1}$, together with the observation of the other weaker bands, suggests that the $\mathrm{I}_{3}$ moiety in 4 is better formulated as an $\mathrm{I}^{-} \cdot \mathrm{I}_{2}$ entity, containing a slightly perturbed diiodine molecule, rather than as an $\mathrm{I}_{3}{ }^{-}$ species. A comparable situation exists for $\left[\left(\mathrm{EtNH}_{2}\right)_{2} \mathrm{dt}\right] \mathrm{I}_{3}$, which exhibits a very strong Raman band at $167 \mathrm{~cm}^{-1}$ and is considered to have a perturbed diiodine molecule [17]. The $\mathrm{I}^{-} \cdot \mathrm{I}_{2}$ formulation for 4 could also be another reason for the similarity of the spectra to those of 3 . The second intense Raman feature observed for 4 at $155 \mathrm{~cm}^{-1}$ may be the result of partial decomposition to another polyiodide species or possibly even site or factor-group splitting of the symmetric $\nu(\mathrm{I}-\mathrm{I})$ vibrational mode. Under pressure, the doublet at 155 and $164 \mathrm{~cm}^{-1}$ shifts gradually to higher wavenumbers, with the higher energy component eventually merging with the lower energy one (Figure 3 ). The versus $\mathrm{P}$ plot in Figure 4 suggests that there is a pressure-induced structural change occurring at $\sim 25 \mathrm{kbar}$. The signals in the $\mathrm{C}-\mathrm{H}$ stretching region are much too weak to be analytically useful at low pressures, but there is a significant increase in intensity occurring in this region, beginning just after the phase transition near $30 \mathrm{kbar}$, that continues until the high est pressure ( $\sim 46 \mathrm{kbar})$ is reached. This dramatic increase in intensity may be associated with pressure-induced fluorescence involving the $\mathrm{I}^{-} \cdot \mathrm{I}_{2}$ entity. Such pressure-induced fluores cence effects have been reported previously for diamond anvils [19], $\mathrm{ZnS}: \mathrm{Mn}^{2+}$ nanoparticles [20], and acetone [21]. In addition, the acridine diiodine $(2: 3)$ adduct has been shown to a yellow-green fluorescence upon exposure to $632.8 \mathrm{He}-\mathrm{Ne}$ laser excitation [22].

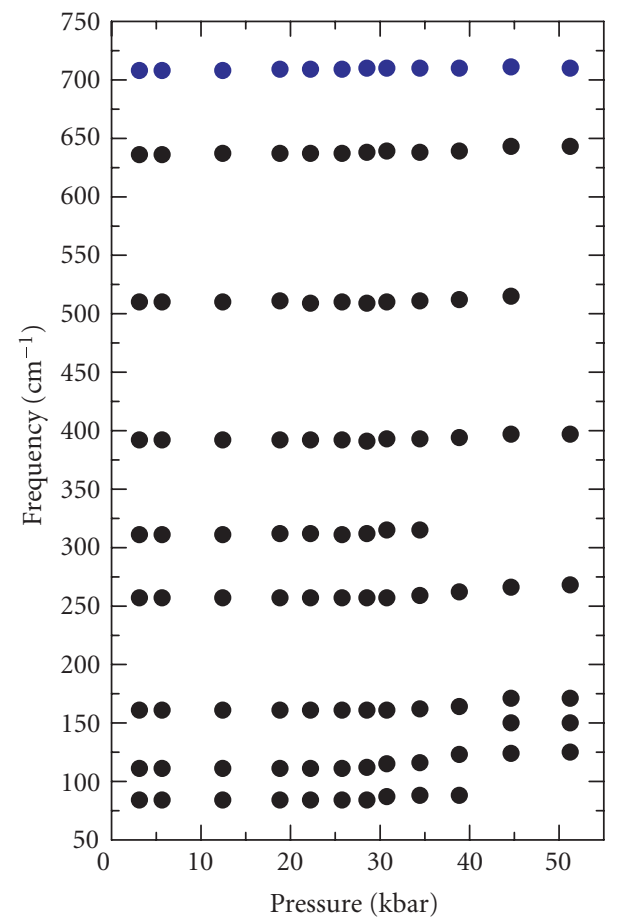

FIGURE 2: Wavenumber versus pressure plot for the FT-Raman spectra of 1 in the low-energy region.

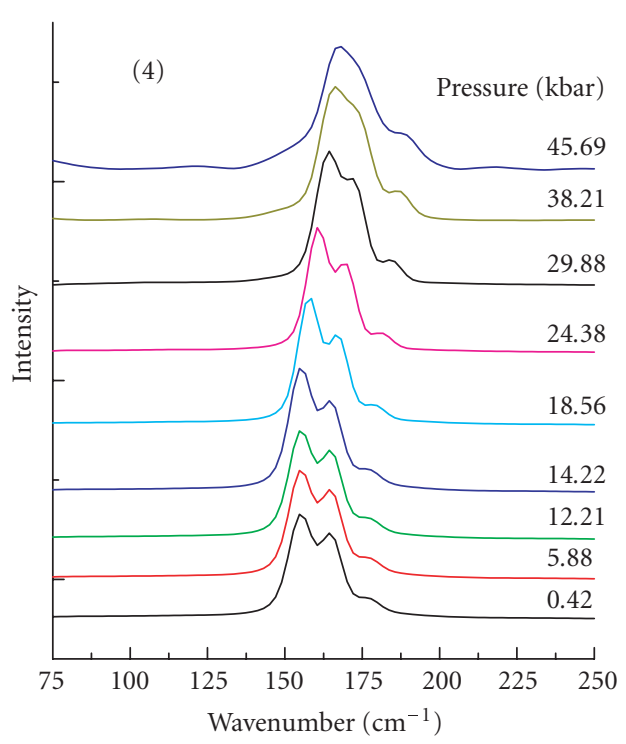

FIgURE 3: Pressure-tuning FT-Raman spectra of 4 in the low-energy region.

Finally, a FT-Raman study was also conducted for compound 5, which it was thought could be formulated as either $($ thpm $)\left(\mathrm{I}_{2}\right)_{2}$ or $\left[(\text { thpm }) \mathrm{I}_{2}\right]^{+}\left[\mathrm{I}_{3}\right]^{-}$(thpm = 2-mercapto3,4,5,6-tertahydropyrimidine). The principal, low-energy features appear at $91 \mathrm{w}, 161 \mathrm{vvs}$ and $197 \mathrm{w} \mathrm{cm}^{-1}$ suggesting the presence of neutral (thpm) $\left(\mathrm{I}_{2}\right)_{2}$, containing perturbed 


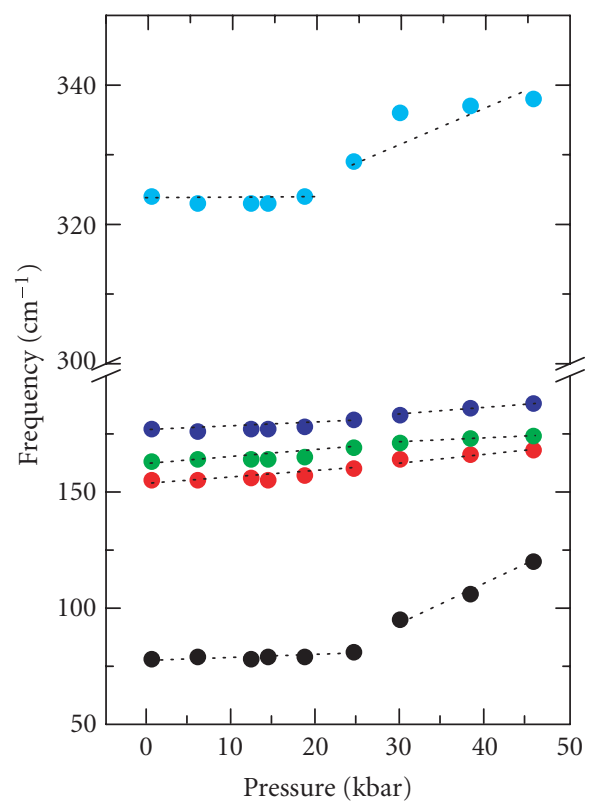

FIGURE 4: Wavenumber versus pressure plot for the FT-Raman spectra of 4 in the low-energy region.

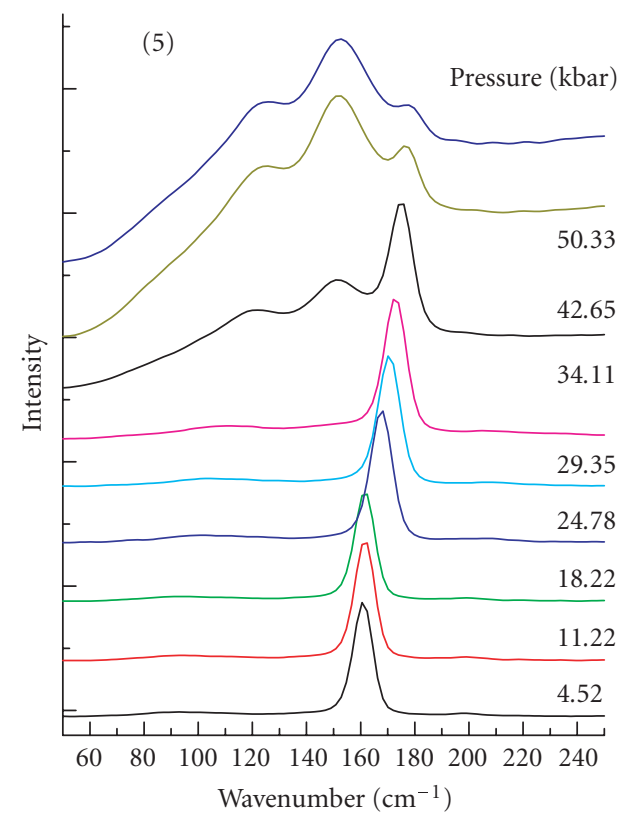

FIGURE 5: Pressure-tuning FT-Raman spectra of 5 in the low-energy region. The unlabeled pressure value is a repeated measurement of the experiment at $50.33 \mathrm{kbar}$ and emphasizes the reproducibility of the pressure-tuning work.

diiodine molecules, rather than ionic $\left[(\text { thpm }) \mathrm{I}_{2}\right]^{+}\left[\mathrm{I}_{3}\right]^{-}$for which the strongest Raman band would be expected at $\sim 110 \mathrm{~cm}^{-1}$ and not at $\sim 160 \mathrm{~cm}^{-1}$. Under pressure, this compound also undergoes a structural change at $\sim 32 \mathrm{kbar}$ (Figures 5 and 6).

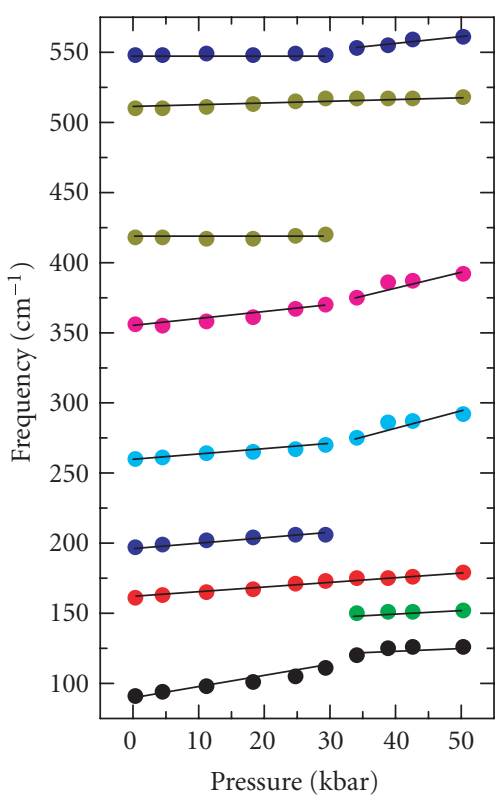

FIgURE 6: Wavenumber versus pressure plot for the FT-Raman spectra of $\mathbf{5}$ in the low-energy region.

\section{CONCLUSIONS}

Raman spectroscopy continues to be an extremely useful probe for examining the structural features of diiodine [14, $15,23]$ and interhalogen [24] thioamide compounds. In the pressure-tuning FT-Raman spectroscopic work reported here, structural phase transitions were detected for compounds $\mathbf{1}, \mathbf{4}$, and $\mathbf{5}$ at $\sim 35, \sim 25$, and $\sim 32 \mathrm{kbar}$, respectively. There was no evidence of any free $I_{2}$ formation for any of the compounds examined under high pressures. The similarity of the FT-Raman spectra of the two pairs of compounds, 1, 2, 3 , and 4 , may be the result of them being closely related perturbed diiodine complexes [25]. In the case of compounds 3 and $\mathbf{4}$, it is also possible that a pressure-induced disproportionation of $\mathbf{3}$ may have occurred leading to the formation of 4 , in a similar manner to the effect of pressure on [(bztzdtH) $\left.\mathrm{I}_{2}\right\} \cdot \mathrm{I}_{2}$ (bztzdtH = benzothiazole-2-thione) [4]. Finally, the FT-Raman data show that $\mathbf{5}$ is best formulated as (thpm) $\left(\mathrm{I}_{2}\right)_{2}$ rather than the ionic species $\left[(\text { thpm }) \mathrm{I}_{2}\right]^{+}\left[\mathrm{I}_{3}\right]^{-}$.

\section{ACKNOWLEDGMENTS}

This work was generously supported by operating and equipment grants to I. S. Butler from the NSERC (Canada) and the FQRNT (Quebec). The award of a NATO Collaborative Research Grant to N. Hadjiliadis, I. S. Butler, and I. Sovago (Hungary) is also gratefully acknowledged.

\section{REFERENCES}

[1] Svensson PH, Kloo L. Synthesis, structure, and bonding in polyiodide and metal iodide-iodine systems. Chemical Reviews. 2003;103(5):1649-1684.

[2] Antoniadis C, Hadjikakou SK, Hadjiliadis N, Kubicki M, Butler IS. Synthesis, X-ray characterisation and studies of the new 
ionic complex [bis(pyridin-2-yl) disulfide] triiodide, obtained by oxidation of 2-mercaptopyridine with $\mathrm{I}_{2}$ - implications in the mechanism of action of antithyroid drugs. European Journal of Inorganic Chemistry. 2004;2004(21):4324-4329.

[3] Boyle PD, Godfrey SM. The reactions of sulfur and selenium donor molecules with dihalogens and interhalogens. Coordination Chemistry Reviews. 2001;223(1):265-299.

[4] dos Santos JHZ, Butler IS, Daga V, Hadjikakou SK, Hadjiliadis N. High-pressure Fourier transform micro-Raman spectroscopic investigation of diiodine-heterocyclic thioamide adducts. Spectrochimica Acta - Part A: Molecular and Biomolecular Spectroscopy. 2002;58(12):2725-2735.

[5] Corban GD. Synthesis, characterization and study of new compounds of diiodine and/or iron with ligands which act or may act as antithyroid drugs. Possible implications of the new compounds in the mechanism of thyroid hormones synthesis [PhD thesis]. Ioannina, Greece: University of Ioannina; 2006.

[6] Corban GJ, Hadjikakou SK, Hadjiliadis N, et al. Synthesis, structural characterization, and computational studies of novel diiodine adducts with the heterocyclic thioamides $N$ methylbenzothiazole-2-thione and benzimidazole-2-thione: Implications with the mechanism of action of antithyroid drugs. Inorganic Chemistry. 2005;44(23):8617-8627.

[7] Demartin F, Deplano P, Devillanova FA, Isaia F, Lippolis V, Verani G. Conductivity, FT-Raman spectra, and X-ray crystal structures of two novel [D2I]In $(n=3$ and $\mathrm{D}=\mathrm{N}$-methylbenzothiazole-2(3H)-selone; $\mathrm{n}=7$ and $\mathrm{D}=\mathrm{N}$-methylbenzothiazole-2 $(3 \mathrm{H})$-thione) iodonium salts. First example of I-.3I2 heptaiodide. Inorganic Chemistry. 1993;32(17):3694-3699.

[8] Antoniadis C. Synthesis, characterization and study of new compounds of diiodine with ligands with possible antithyroid activity (e.g., thioamides). Contribution in the study of the mechanism of action of antithyroid drugs [PhD thesis]. Ioannina, Greece: University of Ioannina; 2005.

[9] Butler IS. High-pressure Raman techniques. In: McCleverty JA, Meyer TJ, eds. Comprehensive Coordination Chemistry II. Chapter 2.9. Amsterdam, The Netherlands: Elsevier; 2004:113-120.

[10] Tezuka T, Nunoue S-Y, Yoshida H, Noda T. Spontaneous emission enhancement in Pillar-type microcavities. Japanese Journal of Applied Physics. Part 2. 1993;32(1):L54-L57.

[11] Qiu CH, Ahrenkiel SP, Wada N, Ciszek TF. X-ray diffraction and high-pressure Raman scattering study of iodineintercalated $\mathrm{Bi}_{2} \mathrm{Sr}_{2} \mathrm{CaCu}_{2} \mathrm{O}_{8+\mathrm{x}}$. Physica C: Superconductivity. 1991;185-189:825-826.

[12] Zhao X-S, Schroeder J, Bilodeau TG, Hwa L-G. Spectroscopic investigations of CdS at high pressure. Physical Review B (Condensed Matter and Materials Physics). 1989;40(2):1257-1264.

[13] Sengupta A, Quitevis EL, Holtz MW. Effect of high pressure on vibrational modes of polyiodides in poly(vinyl alcohol) films. Journal of Physical Chemistry B. 1997;101(51):11092-11098.

[14] Congeduti A, Postorino P, Nardone M, Buontempo U. Raman spectra of a high-pressure iodine single crystal. Physical Review B (Condensed Matter and Materials Physics). 2002;65(1):014302-1-014302-6.

[15] Olijnyk H, Li W, Wokaun A. High-pressure studies of solid iodine by Raman spectroscopy. Physical Review B (Condensed Matter and Materials Physics). 1994;50(2):712-716.

[16] Deplano P, Ferraro JR, Mercuri ML, Trogu EF. Structural and Raman spectroscopic studies as complementary tools in elucidating the nature of the bonding in polyiodides and in donor$\mathrm{I}_{2}$ adducts. Coordination Chemistry Reviews. 1999;188(1):7195.
[17] Deplano P, Devillanova FA, Ferraro JR, Mercuri ML, Lippolis V, Trogu EF. FT-Raman study on charge-transfer polyiodide complexes and comparison with resonance Raman results. Applied Spectroscopy. 1994;48(10):1236-1241.

[18] Ferraro JR. Vibrational Spectroscopy at High External Pressures: The Diamond Anvil Cell. New York, NY: Academic Press; 1984.

[19] Eggert JH, Goettel KA, Silvera IF. Elimination of pressureinduced fluorescence in diamond anvils. Applied Physics Letters. 1988;53(25):2489-2491.

[20] Chen W, Li G, Malm J-O, et al. Pressure dependence of $\mathrm{MN}^{2+}$ fluorescence in $\mathrm{ZnS}: \mathrm{MN}^{2+}$ nanoparticles. Journal of Luminescence. 2000;91(3-4):139-145.

[21] Thurber MC, Hanson RK. Pressure and composition dependences of acetone laser-induced fluorescence with excitation at 248, 266, and $308 \mathrm{~nm}$. Applied Physics B: Lasers and Optics. 1999;69(3):229-240.

[22] Bowmaker G, Knappstein RJ. The low-frequency vibrational spectra of the $1: 1$ acridine-bromine and $2: 3$ acridine-iodine complexes. Australian Journal of Chemistry. 1978;31(10):21312136.

[23] Aragoni MC, Arca M, Demartin F, et al. C.T. complexes and related compounds between $\mathrm{S}$ and Se containing donors and $\mathrm{I}_{2}, \mathrm{Br}_{2}, \mathrm{IBr}$, ICL. Trends in Inorganic Chemistry. 1999;6:1.

[24] Boyle PD, Christie J, Dyer T, et al. Further structural motifs from the reactions of thioamides with diiodine and the interhalogens iodine monobromide and iodine monochloride: an FT-Raman and crystallographic study. Journal of the Chemical Society, Dalton Transactions. 2000:3106-3112.

[25] Deplano P, Devillanova FA, Ferraro JR, Isaia F, Lippolis V, Mercuri ML. On the use of Raman spectroscopy in the characterization of iodine in charge-transfer complexes. Applied Spectroscopy. 1992;46(11):1625-1629. 


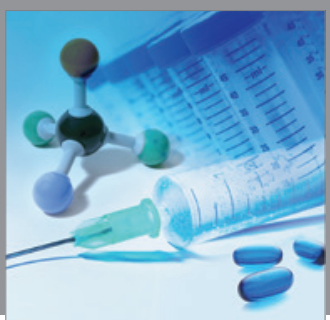

International Journal of

Medicinal Chemistry

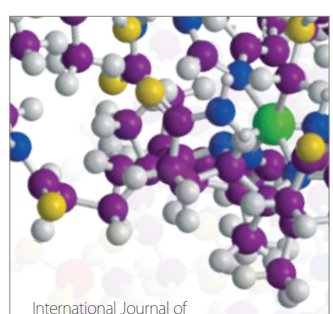

Carbohydrate Chemistry

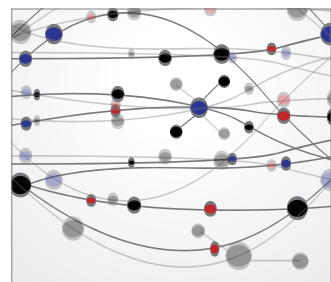

The Scientific World Journal
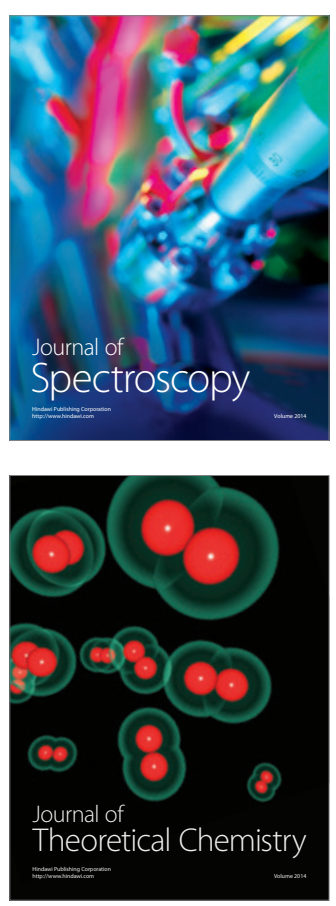
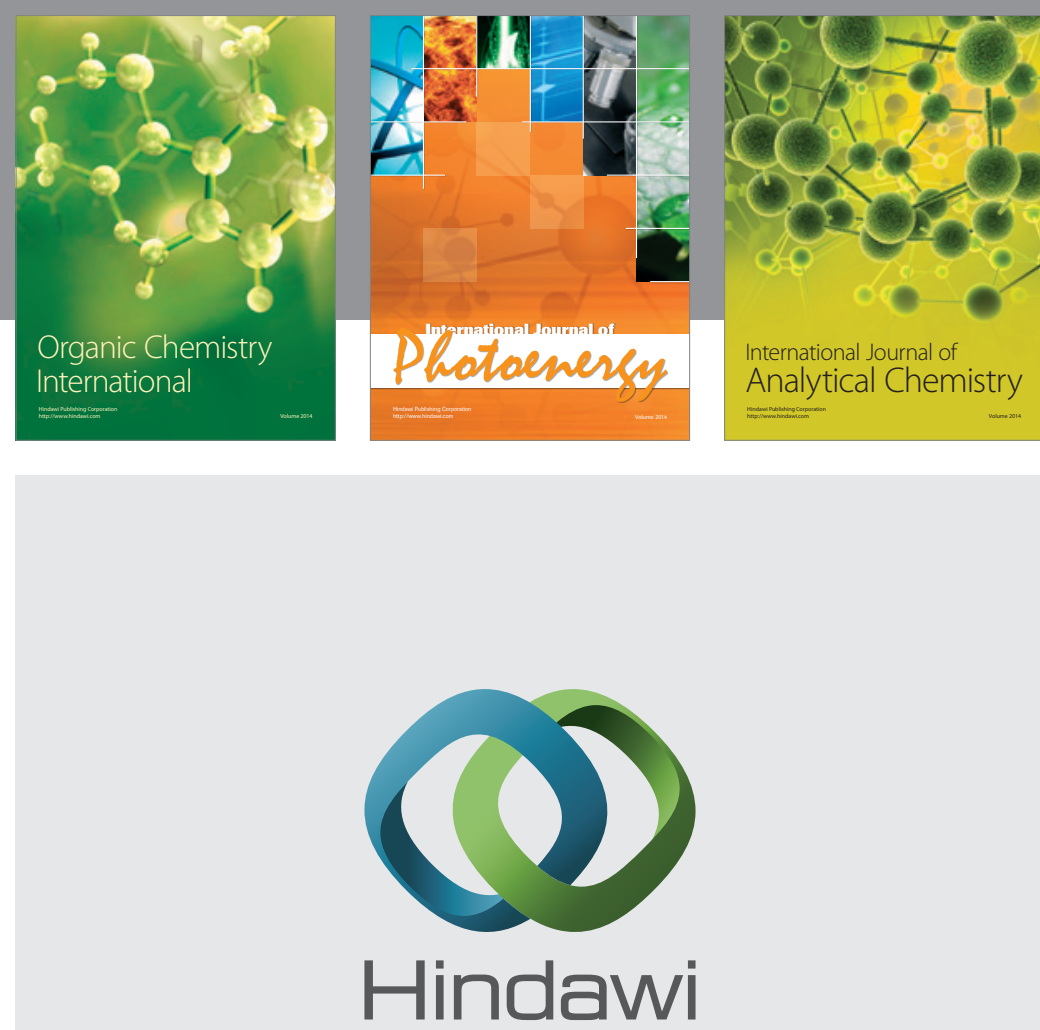

Submit your manuscripts at

http://www.hindawi.com
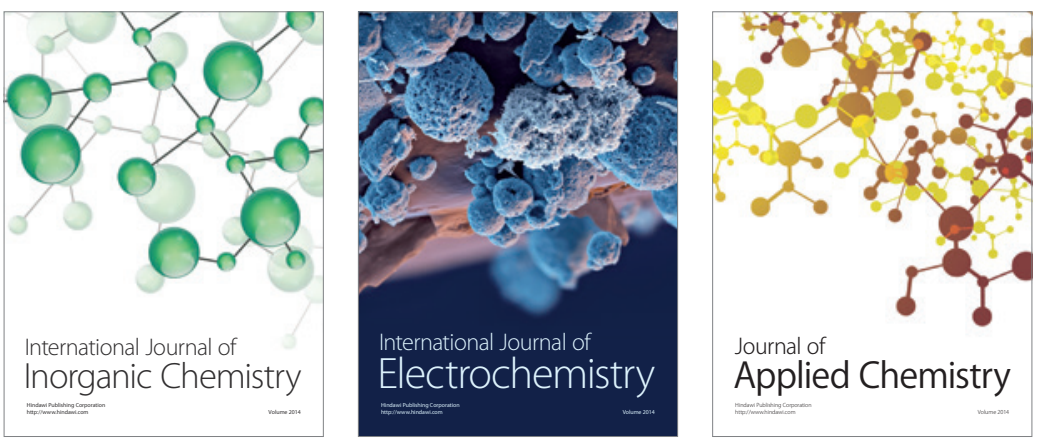

Journal of

Applied Chemistry
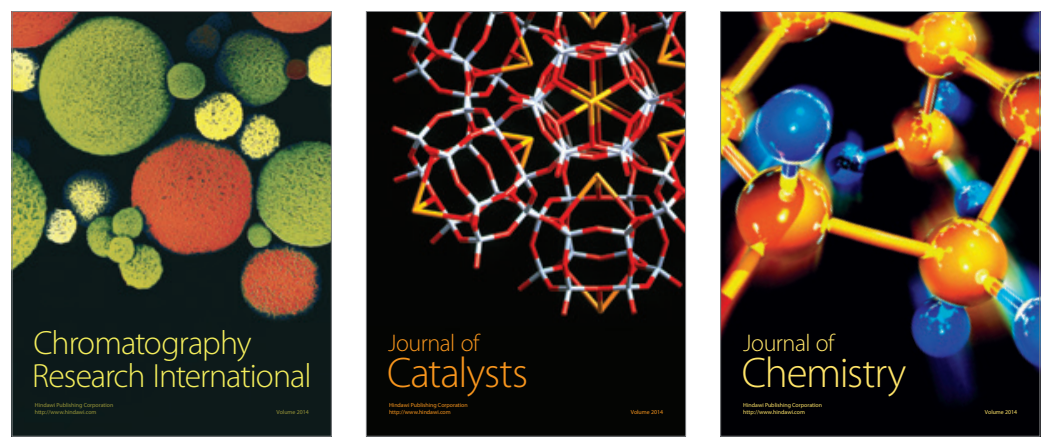
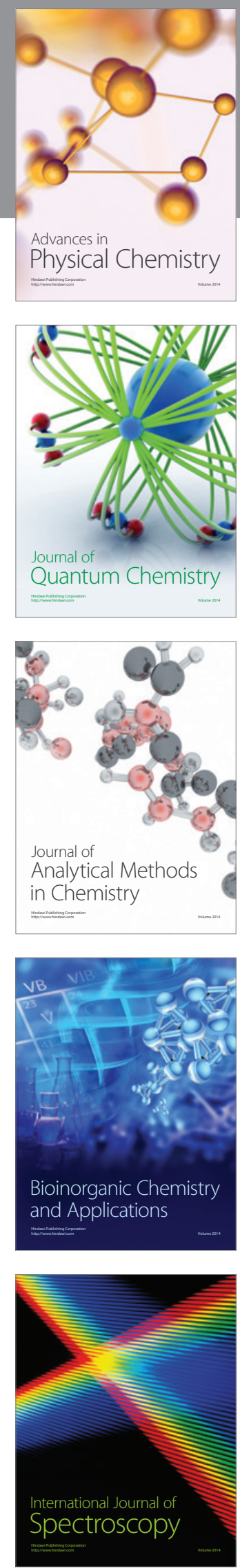